\title{
Assessment of Laparoscopic Mini-Gastric Bypass (LMGB) as A Treatment for Failed Vertical Band Gastroplasty (VBG); Safety and Outcome
}

\author{
MOHAMED ABOUL NAGA, M.D. and MOHAMED MAGDY, M.D. \\ The Department of General Surgery, Faculty of Medicine, Ain Shams University, Cairo, Egypt
}

\begin{abstract}
Background: Bariatric surgery is one of the most successful methods for sustained weight loss in morbid obese patients. Despite the initial success of Vertical Band Gastroplasty (VBG) $10-25 \%$ of patients will require re-operation for unsatisfactory results. Re-operation carries the risk of high morbidity and mortality. The Laparoscopic Mini-Gastric Bypass (LMGB) for revision of failed VBG will be evaluated in this study.
\end{abstract}

Methods: Between January 2015 and March 2017 in Ain Shams University Hospitals 50 patients with failed VBG were enrolled in this prospective study evaluating LMGB as an option for revision.

Results: In our study 50 patients underwent LMGB for revision of failed open VBG, the incidence of intra-operative complications was $6 \%$ and post operative complications was $22 \%$ with significant improvement of BMI after one year of the operation and marked improvement of other symptoms of failure.

Conclusion: At our study LMGB appears to be a safe and sound option as a revisional surgery after open VBG with satisfactory weight loss and less incidence of complications.

Key Words: Mini-gastric bypass - Vertical band gastroplasty - Revision-Morbid obesity.

\section{Introduction}

OBESITY has become one of the most important health issues in developing and developed countries, with dramatic increase over the last decades [1]. Morbid obesity is associated with serious comorbidities, such as type 2 diabetes, hypertension, arthritis, and sleep apnea, which cause an estimated 6 to 12 times greater mortality rate than the normal populations [2]. In the past few years, Vertical Band Gastroplasty (VBG) gained worldwide popularity for the treatment of morbid obesity and was found to be effective in achieving weight loss as

Correspondence to: Dr. Mohamed Aboul Naga, E-Mail: mohamedabonaga@gmail.com well as resolution of co-morbidities with low operative risk [3]. However, in the following years the operation did not achieve optimum results as it was associated with long-term weight gain and some mechanical complications. Later, long-term studies have reported that the rate of conversion surgeries after open VBG ranged from 49.7 to $56 \%$ $[4,5]$. Laparoscopic techniques have greatly increased, and laparoscopic bariatric surgery has been shown to be safe and an effective alternative to open operations. Many investigators have performed RYGBP for redo bariatric surgery either in open or laparoscopic fashion [6]. The Laparoscopic Mini-Gastric Bypass (LMGB), first reported by Rutledge, is a procedure employing a divided long vertical tube gastroplasty in conjunction with a loop gastrojejunal bypass, which causes weight loss by both restriction and malabsorption [7]. The purpose of this study was to evaluate LMGB as a re-do surgery for patients with failed VBG, with special emphasis on operative and posto-perative outcome.

\section{Patients and Methods}

Between January 2015 and March 2017, 50 patients were scheduled for revisional surgery after failed VBG (causes of failure are shown in (Table 2 ) in Ain Shams University Hospitals, 46 females and 4 males with mean age $36.32 \pm 8.72$ with mean Body Mass Index (BMI) before LMGB $42.84 \pm 7.34$ (Table 1).

All 50 patients underwent complete preoperative work-up, including full blood chemistry, endocrine status, upper gastrointestinal barium studies, and gastroendoscopy. Visits to a dietician and psychiatric evaluations were arranged, and explanations for a clear understanding of the ben- 
efits, risks, and long-term consequences of a malabsorptive procedure were done.

Table (1): Demographic data of the patients.

\begin{tabular}{ll}
\hline & Total no. $=50$ \\
\hline Age: & \\
Mean $\pm \mathrm{SD}$ & $36.32 \pm 8.72$ \\
Range & $22-56$ \\
Sex: & \\
Female & $46(92.0 \%)$ \\
Male & $4(8.0 \%)$ \\
BMI before VBG: & \\
Mean \pm SD & $46.87 \pm 8.94$ \\
Range & $35-70$ \\
BMI before MGB: & \\
Mean \pm SD & $42.84 \pm 7.34$ \\
Range & $34-62$ \\
\hline
\end{tabular}

Table (2): Cause of failure of previous VBG.

\begin{tabular}{lc}
\hline Reasons for revision to LMGB & No. of cases \\
\hline Weight regain & $19(38 \%)$ \\
Unsatisfactory weight loss & $17(34 \%)$ \\
Reflux esophagitis & $11(22 \%)$ \\
Stomal stenosis & $3(6 \%)$ \\
\hline
\end{tabular}

The LMGBs were essentially the same as described by Rutledge [7]. The patients were placed in gentle reverse Trendlenburg position, and 5trocars were used (one for the camera, two working ports, one assistant port and one port for liver retractor).

We started each operation by performing a diagnostic laparoscopy and division of adhesions from the previous operation with achieving a full view and orientation of the needed anatomy.

Dissection along the lesser curvature was limited to the distal part of the stomach adjacent to the crows foot, to avoid injury to the blood supply of the gastric tube. Narrow gastric tube, roughly the diameter of the esophagus, was created using the GIA stapler after insertion of a 36-Fr tube as a stent. The retro-gastric space was dissected progressively after each linear stappler application under direct vision up to the angle of hiss and just medial to the previous VBG staple line to decrease the size of the dilated gastric pouch if needed, avoiding injury to the posterior gastric wall.

The small intestine was then explored and the ligament of Tritez was identified with the creation of an anti colic gastro jeujenostomy $200 \mathrm{~cm}$ from the ligament of Tritez, closure of the stoma was done using V-Lock endo-stitch sutures and mythe- lene blue test was done twice in all our patients any bleeding point from the staple line was secured using a hemo clips.

A drain was left for the first 48 hours no ryle tube nor urinary catheter was needed. All patients were followed-up for any complications in the early post-operative period and were followed-up at 3,6 and 12 months for weight loss.

\section{Results}

In this study all the operations were completed laparoscopically except for two patients, which were converted to open surgery due to extensive adhesions in one case and uncontrolled intra operative bleeding in another case, mean operative time was $95 \pm 17.3 \mathrm{~min}$ in the patients completed laparoscopically, all patients were discharged on postoperative day 2 after starting oral intake for 48 hours except for five patients for management of encountered complications.

As regard intra operative complications shown in (Table 3) we had one patient with injury to the splenic vessels with subsequent conversion to open surgery with control of the bleeding and spleenectomy with completion of the operation and also another patient with extensive adhesions. Both patient were calculated statistically for weight loss in this study.

During the early post-operative period 3 patients (6\%) had bleeding evident by $\pm 300 \mathrm{cc}$ blood in the drain and hemodynamic instability, they were managed conservatively by blood transfusion and were discharged after staplization and follow-up CBC. 2 patients had post-operative leakage diagnosed by post-operative CT scan with oral contrast and were managed by placing anti migratory mega stent endoscopically which was removed 6 weeks later with no need for re operation. One month after the operation 6 patients $(12 \%)$ started complaining of symptoms of reflux 5 patients were managed medically with complete resolution at $7 \pm 2$ weeks and 1 patient was scheduled for conversion to LRYGB after failure of medical treatment post-operative complications shown in (Table 4).

As regard weight loss our study showed highly significant improvement of BMI along follow-up at 3,6 and 12 months shown in (Table 5) also patients were subjected for a questionnaire for resolution of symptoms of other causes of failure with complete resolution after 6 months of the operation. 
Table (3): Intra operative complications.

\begin{tabular}{lll}
\hline Intra operative complications & No. & $\%$ \\
\hline Bleeding: & 49 & 98.0 \\
$\quad$ Negative & 1 & 2.0 \\
Positive & & \\
Internal organs injury: & 50 & 100.0 \\
$\quad$ Negative & 0 & 0.0 \\
Positive & & \\
Conversion to open: & 48 & 96.0 \\
$\quad$ Negative & 2 & 4.0 \\
$\quad$ Positive & & \\
\hline
\end{tabular}

Table (4): Post-operative complications.

\begin{tabular}{lll}
\hline Post-operative complications & No. & $\%$ \\
\hline Bleeding: & & \\
Negative & 45 & 90.0 \\
Positive & 3 & 6.0 \\
Leakage: & & \\
Negative & 48 & 96.0 \\
Positive & 2 & 40.0 \\
Reflux gastritis: & & \\
Negative & 44 & 88.0 \\
Positive & 6 & 12.0 \\
\hline
\end{tabular}

Table (5): BMI before LMGB and on follow-up.

\begin{tabular}{|c|c|c|c|c|c|}
\hline & Mean \pm SD & Range & $\begin{array}{c}\text { Test } \\
\text { value• }\end{array}$ & $\begin{array}{c}p- \\
\text { value }\end{array}$ & Sig. \\
\hline $\begin{array}{l}\text { - BMI before } \\
\text { MGB }\end{array}$ & $42.84 \pm 7.34$ & $34-62$ & - & - & - \\
\hline $\begin{array}{l}\text { Post-operative } \\
\text { weight loss after } \\
3 \text { months }\end{array}$ & $37.97 \pm 5.74$ & $31-50$ & 16.799 & 0.000 & HS \\
\hline $\begin{array}{l}\text { - Post-operative } \\
\text { weight loss after } \\
6 \text { months }\end{array}$ & $34.04 \pm 4.67$ & $28-45$ & 17.085 & 0.000 & HS \\
\hline $\begin{array}{l}\text { - Post-operative } \\
\text { weight loss after } \\
1 \text { year }\end{array}$ & $29.22 \pm 3.57$ & $24-37$ & 23.779 & 0.000 & HS \\
\hline
\end{tabular}

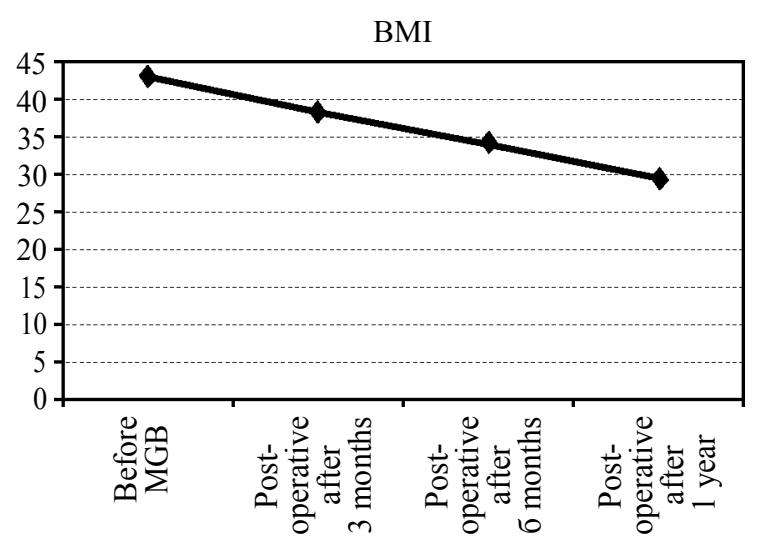

Chart (1): Showing BMI during follow-up.

\section{Discussion}

In the past two decades, VBG was one of the most popular bariatric operations, and was endorsed by the NIH in 1991 because of its technical simplicity, safety and good results [8]. Nevertheless, several reports on long-term follow-up found that VBGs may be associated with long-term failure. Van Gemert et al., [9] reported a failure-rate after VBG of $56 \%$ over a period of 12 years, and more recently, Ortega et al., [10] reported a failure-rate of $50 \%$ after only 2-years follow-up. Over the past years, LRYGB was the most commonly performed conversion surgery after failed open VBG as it achieves good long-term results in weight loss. However, it is associated with a high rate of complications and long-term metabolic side effects [4] It has been reported that revisional bariatric surgery is burdened by high morbidity rates ranging from $12-50 \%$ [11]. Yet in our study the incidence of intra and post-operative complications were $6 \%$ and $22 \%$ respectively and most of them were managed conservatively. Developments made in laparoscopic revisional bariatric surgeries led to the arising of LMGB as a safer substitute to LRYBG, LMGB is superior in the fact that it is associated with single anastomosis with better blood supply for gastric tube decreasing the risk of leakage [12]. In 2005 Gonzalez et al., [13], stated that anastomotic strictures and leaks are relatively high after revisional LRYGB. Later, Gagne et al., [14] stated that strictures are common complication after revisional LRYGB and it occurs because of proximal gastric pouch mucosal thickening or distal pouch ischemia due to chronic inflammation from vertical staple line. So in conclusion LMGB appears to be a safe option for revisional surgery with excellent weight loss and accepted improvement in other causes of failure of VBG.

\section{Conclusion:}

By the end of our study we believe that LMGB is a safe and sound option for revision of failed open VBG in terms of safety and weight loss.

\section{References}

1- DEITEL M.: Overweight and obesity worldwide now estimated to involve 1.7 billion people (Editorial). Obes. Surg., 13: 329-30, 2003.

2- Guidelines for reporting results in bariatric surgery. Standards Committee, American Society of Bariatric Surgery. Obes. Surg., 7: 521-2, 1997.

3- DARGENT J.: Laparoscopic adjustable gastric banding: Lessons from the first 500 patients in a single institution. Obes. Surg., 9: 446-52, 1999.

4- W.G. VAN GEMERT, M.M. VAN WERSCH, J.W.M. GREVE and P.B. SOETERS: "Revisional surgery after 
failed vertical banded gastroplasty: Restoration of vertical banded gastroplasty or conversion to gastric bypass," Obesity Surgery, Vol. 8, No. 1, pp. 21-8, 1998.

5- K. MILLER, A. PUMP, and E. HELL: "Vertical banded gastroplasty versus adjustable gastric banding: Prospective long-term follow-up study," Surgery for Obesity and Related Diseases, Vol. 3, No. 1, pp. 84-90, 2007.

6- LEE W.J., LAI I.R., HUANG M.T., et al.: Laparoscopic versus open vertical banded gastroplasty for the treatment of morbid obesity. Surg. Laparosc. Endosc., 11: 9-13, 2001.

7- RUTLEDGE R.: The mini-gastric bypass: Experience with the first 1,274 cases. Obes. Surg., 11: 276-80, 2001.

8- Gastrointestinal surgery for severe obesity. National Institutes of Health Consensus Development Conference Draft Statement. Obes. Surg., 1: 257-66, 1991.

9- VAN GEMERT W.G., VAN WERSCH M.M., GREVE J.W., et al.: Revisional surgery after failed vertical banded gastroplasty: Restoration of vertical banded gastroplasty or conversion to gastric bypass. Obes. Surg., 8: 21-8, 1998.
10- ORTEGA J., SALA C., FLOR B., et al.: Vertical banded gastroplasty converted to Roux-en-Y gastric bypass: Little impact on nutritional status after 5-year follow-up. Obes. Surg., 14: 638-43, 2004.

11- VAN WAGENINGEN B., BERENDS F.J., VAN RAMSHORST B., et al.: Revision of failed gastric banding to Roux-enYgastric bypass. Obes. Surg., 16: 137-41, 2006.

12- R. NOUN, S. ZEIDAN, E. RIACHI, B. ABBOUD, V. CHALHOUB and A. YAZIGI: "Mini-gastric bypass for revision of failed primary restrictive procedures: A valuable option," Obesity Surgery, Vol. 17, No. 5, pp. 684-8, 2007.

13- R. GONZALEZ, S.F. GALLAGHER, K. HAINES, and M.M. MURR: "Operative technique for converting a failed vertical banded gastroplasty to Roux-en-Y gastric bypass," Journal of the American College of Surgeons, Vol. 201, No. 3, pp. 366-74, 2005.

14- D.J. GAGNE, E. DOVEC, and J.E. URBANDT: "Laparoscopic revision of vertical banded gastroplasty to Roux-en-Y gastric bypass: Outcomes of 105 patients," Surgery for Obesity and Related Diseases, Vol. 7, No. 4, pp. 493-9, 2011.

\section{تقييم عملية تحويل المسار المصغر بالمنظار

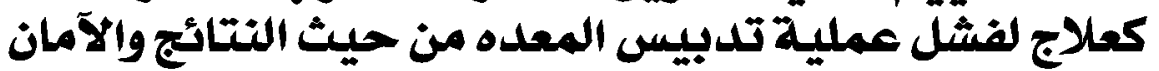

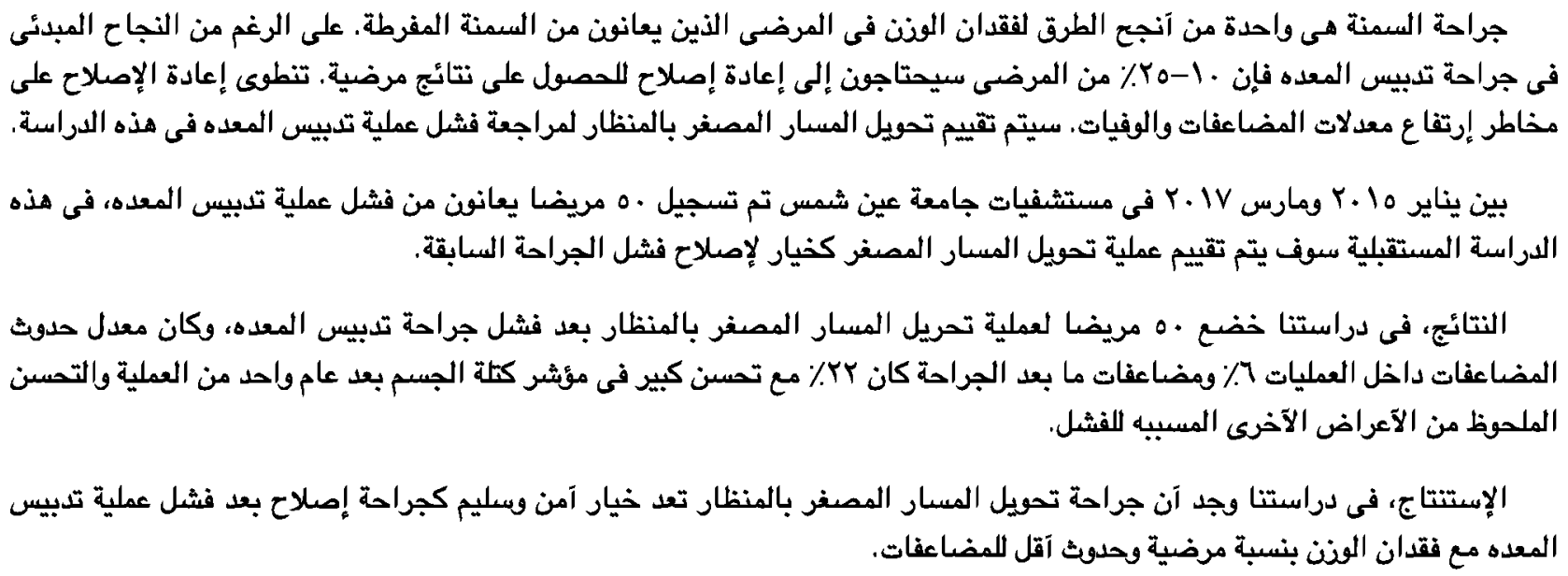

